\title{
Regeneração Óssea Guiada através da membrana Bone Heal
}

\author{
Guided Bone Regeneration through the Bone Heal membrane
}

Recebido: 02/11/2021 | Revisado: 04/11/2021 | Aceito: 06/11/2021 | Publicado: 07/11/2021

\author{
Kamila Keiko Ferreira Pinto \\ Universidade Brasil, Brasil \\ E-mail: milakeikoo@gmail.com \\ Abner Maciel de Oliveira \\ Universidade Brasil, Brasil \\ E-mail: abnermaciel25@gmail.com \\ André Chacon Montesino \\ Universidade Brasil, Brasil \\ E-mail: acmontesino@hotmail.com
}

\begin{abstract}
Resumo
A Odontologia está cada vez mais se desenvolvendo a pensamentos que visam a preservação dos tecidos orais. Porém, devido a patologias como: doenças periodontais e cárie em estágios avançados, a extração de elementos dentais tornase a única opção viável naquele momento. $\mathrm{O}$ processo de regeneração óssea posterior à extração é fundamental para a possível reabilitação através de próteses e/ou implantes. A regeneração óssea guiada realizada com a utilização de materiais reabsorvíveis ou não, está cada vez mais se difundindo pela Odontologia. Com o objetivo de realizar a busca dos artigos para a revisão de literatura foi utilizada as bases de dados: Google Scholar, Bireme, Pubmed, Lilacs. Artigos selecionados para a delimitação do tema e confecção do trabalho. Neste presente documento, irá ser abordada a utilização da membrana não absorvível, Bone Healß (barreira de polipropileno, exposta intencionalmente na cavidade oral), na manutenção e preservação do coágulo formado no alvéolo pós-exodontia, corroborando para um processo de reparação óssea mais estável e diminuindo, consequentemente, perdas dimensionais ósseas exacerbadas.

Palavras-chave: Extração; Coágulo sanguíneo; Reabsorção óssea; Regeneração óssea-guiada; Bone Heal; Reparação óssea.
\end{abstract}

\begin{abstract}
Dentistry is increasingly developing thoughts aimed at preserving oral tissues. However, due to pathologies such as periodontal diseases and caries in advanced stages, the extraction of dental elements becomes the only viable option at that time. The process of bone regeneration after extraction is essential for possible rehabilitation through prostheses and/or implants. Guided bone regeneration performed with the use of resorbable or non-resorbable materials is increasingly spreading in Dentistry. In order to carry out the search for articles for the literature review, the following databases were used: Google Scholar, Bireme, Pubmed, Lilacs. Selected articles for the delimitation of the theme and preparation of the work. In this document, the use of the non-absorbable membrane, Bone Heal@ (propylene barrier, intentionally exposed in the oral cavity), will be addressed in the maintenance and preservation of the clot formed in the post-extraction alveolus, contributing to a process of bone regeneration more stable and, consequently, decreasing exacerbated bone dimensional losses.
\end{abstract}

Keywords: Extraction; Blood clot; Bone resorption; Guide bone regeneration; Bone Heal; Bone repair.

\section{Introdução}

O conceito de Mínima Invasão na Odontologia está se propagando cada vez mais, embasado em diversos estudos sobre o comportamento das patologias que mais acometem e trazem danos significativos à saúde oral: doença periodontal e cárie (e as consequentes lesões periapicais crônicas que podem se desenvolver através dela). Com base nessas novas informações, muitas condutas em relação ao tratamento dos elementos dentais estão sendo alavancados, e políticas de preservação e manutenção dos elementos dentais se destacam frente a condutas consideradas mais radicais. (Tumenas et al., 2014). 
A extração de elementos dentais, antes utilizada como única alternativa para a "solução" de patologias que acometessem a cavidade oral, atualmente torna-se uma das últimas alternativas de cessação da sintomatologia dolorosa derivada de processos patológicos. Porém, há casos em que a extração se torna a opção de eleição, devidos a fatores biológicos ou não. (Santos et al., 2019).

O processo de extração dentária é fisiologicamente relacionado com a atividade óssea alveolar da região, já que na constituinte anatômica, osso alveolar e dentes estão intimamente conectados. Toda extração irá trazer consequências variáveis na dinâmica fisiológica de modelação e remodelação óssea, e conseguinte, reabsorção óssea do osso alveolar restante. (Lam em Salomão \& Siqueira, 2010).

Diversos estudos surgem no cenário odontológico buscando alternativas para uma regeneração óssea mais dinâmica afim de diminuir uma perda acentuada na dimensão vertical e horizontal dos rebordos alveolares nas paredes linguais e, principalmente, vestibulares dos alvéolos. A Regeneração Óssea Guiada, desenvolve-se então com a implementação de materiais biocompatíveis que visam a melhores resultados de regeneração nos processos de modelação e remodelação óssea através da Osteopromoção. (Petrilli et al., 2018; Salomão \& Siqueira, 2010; Liu \& Kerns, 2014).

Dentre esses materiais, encontra-se a membrana não-absorvível Bone Heal ®, material constituído de um filme de polipropileno, biocompatível, bioinerte e impermeável que através de sua ação como barreira mecânica, possibilita ao coágulo sanguíneo um processo de reparo mais dinâmico, auxiliando na preservação óssea do rebordo alveolar. (Salomão \& Siqueira, 2010).

A adaptação de próteses removíveis e/ou instalação de implantes na região, dependem exclusivamente das condições do rebordo alveolar restante na região. Se o mesmo não se encontrar em condições minimamente favoráveis, todo este processo reabilitador é comprometido. (Santos, 2012).

O presente trabalho tem como objetivos apresentar as informações sobre o processo de Regeneração Óssea Guiada através do uso da membrana de polipropileno, que propositalmente, fica exposta ao meio bucal; o entendimento sobre a constituição, funcionamento e processo de reparação óssea; a importância da integridade do coágulo sanguíneo no interior do alvéolo pós-exodontia e a conseguinte manutenção da altura alveolar; as características da membrana Bone Heal @ e o passo a passo de sua utilização.

\section{Metodologia}

Este estudo utiliza como natureza qualitativa, visando compreender utilização da membrana não absorvível, Bone Heal® (barreira de polipropileno, exposta intencionalmente na cavidade oral), na manutenção e preservação do coágulo formado no alvéolo pós-exodontia, corroborando para um processo de regeneração óssea mais estável e diminuindo, consequentemente, perdas dimensionais ósseas exacerbadas. (Pereira et al, 2018).

Os critérios de inclusão foram os seguintes: artigos e revistas, disponível nos idiomas em língua inglesa, espanhola e portuguesa nos sites como: Google Scholar, Bireme, Pubmed, Lilacs, Scielo, Bone Heal®, contextos disponíveis em meios eletrônicos, além de 3 livros relacionados com os assuntos. Foram selecionados 32, nos idiomas: inglês, português e espanhol, com recorte temporal 1960 a 2021. Os critérios de exclusão: relatórios e publicações sem fontes confiáveis, materiais com disponibilidade incompleta que não abordava com clareza o tema. 


\section{Resultados e Discussão}

\subsection{A extração dentária e seus efeitos}

A extração dentária durante grande parte da história da Odontologia foi a alternativa recorrente para tratamento de patologias. Mais especificamente, a extração foi o tratamento de eleição para a cessação do processo de dor, em casos agudizados ou não.

Apesar de ao longo dos anos novas técnicas de tratamento que visam à preservação de estruturas dentais se desenvolverem, através da nova linha de pensamento e planejamento da Odontologia Preventiva, a Odontologia Mutiladora ainda segue presente como terapêutica para alguns casos, em especial, aqueles que refletem o acúmulo de patologias bucais. Ações de conservação e manutenção dos elementos dentais constituem a base da terapêutica moderna, porém há alguns fatores que impossibilitam esses tratamentos, resultando no processo de extração dentária. (Fernandes, et al., 2010).

Fatores etiológicos biológicos como: doença periodontal; lesões de cárie; patologias pulpares e traumas podem resultar em extração dentária. Assim como, alguns fatores etiológicos não biológicos como: condições financeiras, psicológicas e sociais; acesso ao tratamento odontológico e qualidade do tratamento realizado podem culminar em processos de extração. (E. Santos et. al., 2019).

O edentulismo viabiliza ao indivíduo diversas alterações fisiológicas, funcionais, sociais e estéticas. A qualidade de vida de indivíduos com perda dentária é relativamente diminuída. Fenômenos nutricionais, fonéticos, estéticos são afetados diretamente pela ausência de elementos dentais e as consequências deste processo, como a diminuição da DVO provocada pela reabsorção óssea, dificultam a adaptação de futuras próteses e/ou instalação de implantes. (Santos et. al., 2019).

A reabsorção e remodelação óssea são resultantes de um processo natural de cicatrização e ocorrem inevitavelmente após a extração de um elemento dental. A reabsorção das cristas alveolares ocorre de modo a atingir tanto altura quanto largura. As variações médias em altura podem variar entre $1,5 \mathrm{~mm}$ a $2 \mathrm{~mm}$ e em relação a largura, esta pode variar aproximadamente entre 40 a $60 \%$ de espessura do rebordo. Salientando ainda que, a reabsorção óssea em altura (e principalmente na parede vestibular) é mais prevalente do que em largura (perda horizontal que já compromete tanto vestibular quanto lingual/palatina). (Liu \& Kerns 2014; Salomão \& Siqueira, 2010).

Segundo Martinez, estudos indicam que nas primeiras 8 semanas pós-extração, realizada em modelo de animal de cão, há intensa atividade osteoclástica responsável por promover a reabsorção das paredes linguais e vestibulares das paredes óssea. (Martinez, 2013).

A reabilitação através de próteses e implantes é realizada com base na quantidade de osso alveolar remanescente e consequente arquitetura da crista alveolar, sendo assim, a preservação de tecido ósseo de grande valia para uma reabilitação funcional e estética. Em situações em que o rebordo, o qual será tratado de forma reabilitadora, não se encontrar em condições minimamente et al., 2003; J. Santos, 2012; Petrilli et al., 2018).

\subsection{A constituição óssea e osteogênese}

O processo de formação óssea durante a embriogênese, é formado através de um tecido conjuntivo primário. Assim como nos ossos longos, o osso constituinte da maxila e mandíbula fazem parte deste processo, conhecido como formação óssea intramembranosa, que se diferencia da endocondral por não apresentar uma fase cartilaginosa anterior. (Marzola, 2008, p.843).

Nesta constituinte óssea, as células mesenquimais proliferam, agrupam-se e diferenciam-se em áreas mais condensadas de tecido conjuntivo, onde irão ser formadas posteriormente os ossos. Com influência de fatores intrínsecos e locais, uma matriz orgânica repleta de vasos sanguíneos e com a presença de fibroblastos e células osteoprogenitoras começam a se formar. (Judas, 2012). 
O osso é um tecido com grande atividade metabólica e que apresenta multifunções para o nosso organismo. A composição óssea possibilita este tecido a apresentar resistência a cargas; proteção de tecidos sensíveis e mais vulneráveis, sustentação e homeostasia corporal através de reservatórios minerais e o controle de cálcio plasmático. (Henn, 2019).

“O osso é um tecido conjuntivo especializado que é principalmente caracterizado pela mineralização da sua matriz orgânica. A matriz orgânica do tecido óssea é composta de colágeno, proteínas não-colágenas e proteoglicanas. Dentro da matriz, íons de cálcio e fosfato são dispostos na forma de hidroxiapatita". (Marzola, 2008, p. 843).

Como qualquer parte do corpo humano, o osso é formado por células, dentre elas destacam-se as séries dos osteoblastos e osteoclastos, células responsáveis por constantes modificações na arquitetura óssea através do processo de remodelamento ósseo, presente em toda vida do ser humano. (Judas, 2012).

Os odontoblastos são as células ósseas sem a capacidade de proliferação e migração, localizadas na superfície óssea e são responsáveis pela síntese de colágeno e substância fundamental (presentes na formação do osteoide, a matriz orgânica ainda não calcificada) assim como pela calcificação desta matriz orgânica. Eles podem ser originados através das células mesenquimatosas indiferenciadas e pluripotenciais (células osteoprogenitoras), que se diferenciam e transformam-se em osteoblastos, a partir de uma série de eventos genéticos e metabólicos. (Judas, 2012; Henn, 2019).

A osteogênese está intimamente conectada com o crescimento de tecido vascular da área e devido a essa relação, as células perivasculares, são consideradas as principais células osteoprogenitoras, já que os mesmos revestem as paredes de vasos sanguíneos e têm a capacidade de interação com as demais células de onde estejam. (Marzola, 2008).

Os osteoclastos são as células ósseas localizadas na superfície óssea, especialmente no endósteo e são responsáveis pela reabsorção óssea através da liberação de ácidos e enzimas proteolíticas sobre a matriz inorgânica e orgânica, consecutivamente. Exercem papel fundamental no modelamento e remodelamento ósseo. Eles podem ser originados de células precursoras hematopoiéticas, como os monócitos-macrófagos. Destacando novamente, a relação entre o tecido vascular e o ósseo. (Judas, 2012; Henn, 2019; Marzola, 2008).

Os osteócitos são localizados na matriz inorgânica, entre as lacunas ósseas e são responsáveis pela comunicação entre as células ósseas (osteoblastos, osteoclastos, células de revestimento ósseo) e através desta comunicação, os osteócitos são considerados células mecanossensoras, que captam os estímulos mecânicos sobre o osso e as alterações que ocorrem na matriz celular óssea e as transmitem para os osteoblastos e osteoclastos. Por isso, são células de importante papel no processo de remodelação óssea. (Gusmão \& Belangero, 2009).

\subsection{A reparação óssea}

Após a extração dentária, uma série de eventos ordenados que sinalizam o reparo fisiológico dos tecidos lesados durante o procedimento cirúrgico, ocorrem concomitantemente, denominada de reparação óssea. (J. Santos, 2012).

As células osteogênicas são personagens extremamente importantes na reparação óssea, através delas a sequência ordenada de fenômenos fisiológicos ocorre de modo a visarem uma cicatrização do rebordo. Essas células são encontradas principalmente no periósteo, endósteo das paredes do alvéolo, assim como, na medula óssea a partir de células mesenquimais indiferenciadas (que podem ser diferenciar em osteoblastos na presença de determinadas moléculas e fatores de crescimento). Como já relatado, os osteoblastos possuem a capacidade de síntese de matriz orgânica e sua calcificação, importante fenômeno na arquitetura óssea. (Marzola, 2008; Henn, 2019).

A formação de um coágulo no alvéolo e a consequente resposta inflamatória, são desenvolvidos seguidamente da exodontia, em 24 horas. O coágulo é repleto de fatores de crescimento, plaquetas e uma rede de fibrina ao entorno, responsáveis essenciais do processo de regeneração óssea alveolar e reparação óssea. Os neutrófilos são as primeiras células a chegarem na região e promovem a destruição bacteriana através da liberação de radicais livres, logo após este processo a 
tendência é a de os neutrófilos darem lugar a outro tipo de células, os macrófagos. (Salomão \& Siqueira, 2010; Liu \& Kerns, 2014).

Em 48-96 horas, tende a desenvolver-se o tecido de granulação no fundo do alvéolo e a epitelização da ferida a partir das bordas do tecido mole. Macrófagos migram para a região e iniciam um processo de replicação, secreção de citocinas e fatores de crescimento. Toda esta proliferação contribui com a angiogênese, fibroplasia e síntese de matriz provisória de tecido conjuntivo, rica em colágeno que após ser invadida por novos vasos sanguíneos e consequente, células ósseas forma o osteóide primário. (Salomão \& Siqueira, 2010; Liu \& Kerns, 2014).

Em duas ou três semanas, torna-se visível em radiografia, o início da calcificação do alvéolo partindo então de sua base até a região mais superior, passando então para uma conformação de osso esponjoso (que pode permanecer durante semanas até a remodelação óssea e substituição para osso lamelar) concomitante ao processo de reepitelização da ferida óssea. A partir do $100^{\circ}$ dia, a calcificação completa do alvéolo já pode ser acompanhada radiograficamente. (Santos, 2012; Lindhe et al., 2010).

Após seis semanas de cicatrização, a formação óssea no alvéolo é evidente e apresenta trabéculas de osso recémformado. A remodelação óssea, responsável pela substituição da lâmina própria pelo osso lamelar pode demorar meses até seu processo completo e é variável entre indivíduos. (Correia, 2016).

Após dois meses (oito semanas) de cicatrização, ainda se identificam restos do coágulo no centro do alvéolo. Este hematoma está repleto de vasos sanguíneos e de tecido de granulação que posteriormente se tornará um tecido ósseo. (Todescan et al., 2005).

Aos três meses (12 semanas) o tecido já formado primariamente é um diferente do osso esponjoso com trabéculas menores e porosidade menor. As suas trabéculas ósseas são divergentes, sendo os espaços intertrabeculares são amplos e com vasos longos e finos. (Todescan et al., 2005).

Aos quatro meses (16 semanas) existe a formação de um tecido cortical nas bordas mesiais e distais do defeito ósseo. E também de um osso esponjoso, ou seja, um tecido mais medular e de menor peso. Os espaços intertrabeculares se reduzem e começa a aparecer um osso de tipo laminar (formado por lâminas de tecido ósseo compacto com o objetivo de oferecer proteção). Após os quatro meses as superfícies ósseas estão cobertas por osteoblastos e o osteóide por osteoclastos. Calcificando todo o tecido restante. (Todescan et al., 2005).

\subsection{A regeneração óssea guiada}

A reabsorção óssea resultante do processo de extração inevitavelmente é atriz principal da dimensão em largura e altura dos rebordos alveolares, a Regeneração Óssea Guiada surge na Odontologia como um procedimento cirúrgico que visa a utilização de membranas como barreira e a utilização ou não, de substitutos ósseos, como os enxertos ósseos a fim de garantir uma regeneração tecidual de maior qualidade. (Liu \& Kerns 2014; Carvalho, 2014).

Del Rio Rocha, Romero e Díaz (2021) comentam que a utilização de membranas contribui para evitar a infiltração de células indesejáveis na reparação óssea (epiteliais e conjuntivas), preservando a integridade e funcionalidade do coágulo formado na região, promovendo uma atividade de células osteoprogenitoras de maneira mais efetiva possível. E então, disponibilizando uma qualidade e quantidade de osso capaz de promover uma reabilitação satisfatória.

Martinez (2013) ainda defende que a utilização de membranas, como barreiras físicas e mecânicas, possibilita a manutenção das dimensões ósseas e a redução da gravidade de defeitos ósseos causados pós-exodontia.

Para garantir do sucesso da ROG, alguns princípios precisam ser respeitados, como: a exclusão do epitélio e do tecido conjuntivo (células não osteogênicas); adequada vascularização; criação do espaço para estabilidade e formação do coágulo de 
fibrina e fechamento primário da ferida para a promoção da cicatrização mecanicamente estável. (Liu \& Kerns, 2014; Salomão \& Siqueira, 2010).

\subsection{A Osteopromoção}

A Osteopromoção é baseada no princípio de preservar o alvéolo, buscando que a angiogênese e osteogênese ocorram de forma mais eficaz possível, reduzindo e impedindo que as células epiteliais do tecido conjuntivo frouxo, com rápido poder de proliferação, invadam o alvéolo e ocupem o lugar de células sanguíneas e osteoprogenitoras. Reduzindo, assim, significantemente defeitos ósseos que possam ocorrer naquele local após exodontia, em especial naqueles em que não há a presença de todas as paredes circundantes, e essas células indesejáveis tendem a migrarem ainda mais rapidamente. (Carvalho, 2012; Elgali et al., 2017; Todescan et al. 2005).

Assim como relatam Pilger et al. (2020) as células constituintes da cavidade oral possuem diferentes velocidades de migração e proliferação. As células epiteliais do tecido conjuntivo frouxo, possuem rápida proliferação e migração quando comparadas com as células ósseas, por exemplo. Com o uso de membranas, sejam elas absorvíveis ou não absorvíveis, há uma barreira mecânica promovendo então, a preservação do coágulo no alvéolo, impedindo a invasão dessas células conjuntivas frouxas a ocuparem e diminuírem o espaço do local em que células ósseas se desenvolveriam e promoveriam uma melhor regeneração óssea.

Diversos estudos sobre a utilização de membranas na ROG desenvolveram-se e continuam a se desenvolverem durantes anos. Os primeiros estudos e relatos da utilização delas na Odontologia foram relatados por Bjorn em 1964 que já contou com o conceito, ainda não definido na época, de Osteopromoção através da "exclusão do epitélio do processo de cicatrização" assim como relata Vargas (2016).

Liu e Kerns (2014) defendem ainda que a utilização de membranas, além de promover a estabilidade de um coágulo sem a proliferação de células do tecido conjuntivo frouxo, pode trazer outros benefícios para o local da extração, como: proteção contrarruptura do coágulo por ação mecânica e contaminação salivar.

Algumas características são desejadas para este tipo de material, dentre elas estão: biocompatibilidade; capacidade de manutenção do espaço; oclusividade celular; integridade estrutural e facilidade de uso. (Pilger et al., 2020; Costa et al., 2016; Liu \& Kerns, 2014).

Biomateriais são materiais que sejam inertes farmacologicamente e que tenham a capacidade de interação com um organismo vivo, sem provocar reações adversas no local onde foi implantado, ou no sistema em geral deste organismo. As membranas podem apresentar-se em diversos biomateriais, e a partir deles, há a classificação de membranas absorvíveis e membranas não absorvíveis. (Costa et al., 2016).

\subsection{A membrana Bone-Heal}

Bone Heal® é uma película biocompatível, não-reabsorvível, impermeável, constituída 100\% por um filme de polipropileno (PP). Projetada para permanecer exposta intencionalmente ao meio bucal, não apresenta porosidade em sua superfície, o que lhe confere total impermeabilidade dificultando o acúmulo de detritos, restos alimentares e microrganismos em sua superfície. (Salomão \& Siqueira 2010).

Salomão e Siqueira (2010) ainda relatam que o material do qual a membrana é feita, o polipropileno (material aloplástico biocompatível), é utilizado em outras áreas da saúde, como em cirurgias na Medicina, sendo um exemplo, a utilização de telas de polipropileno em cirurgias abdominais. O material apresenta um ótimo comportamento quando utilizado na cavidade oral. 
As indicações e contraindicações foram retiradas do Manual de Instruções de Uso do produto. É indicada em todos os casos no qual foi realizado exodontia e principalmente quando houve perda de alguma parede óssea alveolar. Pode ser utilizado em casos de implante imediato e em locais com pequenas fenestrações ósseas.

As contraindicações da membrana indicadas pelo fabricante são: casos com processos agudos infecciosos e pacientes, que por razões diversas, não possam realizar procedimentos cirúrgicos orais.

As contraindicações relativas podem ser direcionadas a pacientes com má higienização oral, desfavorecendo o processo de cicatrização/reparo e pacientes fumantes. Até o momento, não foi relatado caso de hipersensibilidade ao uso da membrana, mas caso ocorra, o fabricante aconselha que a mesma seja removida.

A biocompatibilidade da membrana possibilitou uma indicação e emprego (além do já indicado): a utilização de forma não exposta ao meio bucal. No caso, a implementação da barreira sob levantamento de seio e enxerto ósseo para evitar uma migração de tecido para o interior do seio maxilar e posterior sutura do retalho, recobrindo totalmente a membrana e conseguindo ótimos resultados de preservação da área desejada, caso clínico relatado por Lacerda (2012).

Alguns autores como Soares, Salomão e Siqueira (2019), Carvalho (2012) e G. Santos (2014) pontuam que essa barreira é altamente viável, sobretudo porque contribui para reduzir a morbidade de cirurgias grandes e traumáticas. Ao contrário das membranas absorvíveis que podem vir até a requererem o uso de materiais de enxerto para estabilização das mesmas nos locais desejados, grandes incisões e retalhos para fechamento primário.

O fechamento primário do tecido mole é imprescindível para manutenção do coágulo e fenômenos de cicatrização. Com a colocação de material de enxerto, isso torna-se ainda mais importante para o sucesso da ação do material. Com o uso de membranas reabsorvíveis, foram encontrados alguns relatos de cobertura insuficiente e recessão gengival e posterior colonização bacteriana, comprometendo todo o processo de regeneração tecidual da área. (Liu \& Kerns, 2014).

Liu e Kerns (2014) e Martinez (2013) ainda sinalizam que outra característica válida a ser destacada da Bone Heal® é a não necessidade de materiais de fixação, como mini parafusos de titânio ou tachas, para a fixação da mesma sobre o defeito ósseo, fato este que é necessário em membranas reabsorvíveis. A membrana de PP tem capacidade de se manter como uma barreira mecânica exposta somente contando com suas características, como rigidez e superfície sem presença de porosidades. Excluindo a necessidade de novo procedimento cirúrgico para remoção de material bioinerte, reduzindo custos e incômodos ao paciente.

Essa autora observa também que tal técnica evita que haja o infiltrado de células de tecido conjuntivo frouxo no interior do alvéolo, o que vem a favorecer a produção de células ósseas em seu interior. partindo então do princípio de Osteopromoção, já relatado nesta revisão. O coágulo que fica dentro do alvéolo, é muito rico em suprimento de plaquetas, nesse procedimento, é substituído, posteriormente, por tecido de granulação impedindo que o tecido conjuntivo invada a área a ser regenerada, favorecendo a ocorrência da regeneração óssea.

Além disso, uma série de outras características que promovem diversas vantagens da utilização da Bone Heal@ é defendida por Salomão (2010), dentre elas podemos destacar:

- Perfeita adaptação da membrana ao defeito ósseo;

- Alto índice de previsibilidade;

- As suturas não necessitam de grandes retalhos e os mesmos não exercem pressão sobre a barreira;

- As diástases são preenchidas somente com sangue;

- Totalmente impermeável, sem porosidades e esterilizada a raios Gama;

- Dispensa procedimento cirúrgico e pode ser removida entre sete e 10 dias;

- Não sofre aderência, nem degradação dos tecidos; 
- Não interfere na formação e organização do coágulo;

- Baixo custo;

- Registrada na ANVISA

- Pronta para utilização dispensando processos de hidratação ou acréscimo de nenhum outro material à sua superfície;

- Promove conforto para paciente e cirurgião-dentista, entre outras.

\subsubsection{Técnica da utilização da Bone-Heal}

Todas as informações contidas neste tópico foram retiradas do manual de instruções de uso do produto.

$1^{\circ}$ Passo: Retirar da embalagem externa, a embalagem lacrada. Remover papel cirúrgico e despejar delicadamente o conteúdo sobre o campo estéril;

$2^{\circ}$ Passo: Abrir a embalagem estéril com a barreira em seu interior;

$3^{\circ}$ Passo: Recortar a barreira com tesoura no formato desejado (Figura 1). A barreira deve cobrir totalmente o defeito ósseo, ultrapassando cerca de dois a três milímetros das bordas da área de defeito (Figura 3). Esta deve estar totalmente preenchida por sangue, garantindo a formação e manutenção do coágulo (Figura 2). (Não há necessidade de aparatos para fixar a barreira).

Figura 1 - Membrana sendo recortada após ser retirada da embalagem estéril.

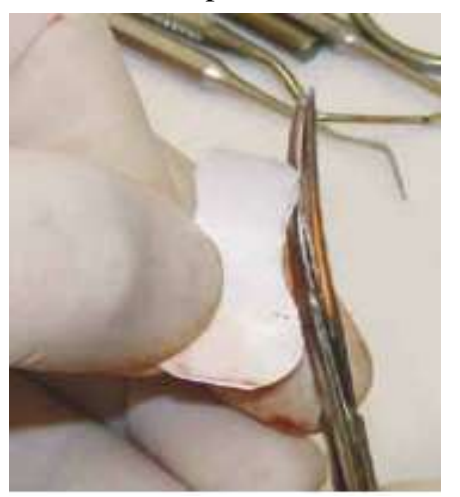

Fonte: Salomão, Siqueira e Alvarez. (2010).

Figura 2 - Local do defeito ósseo preenchido por sangue após extração.

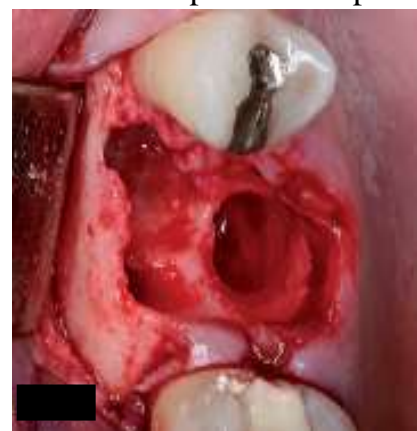

Fonte: Petrilli et al. (2018). 
Figura 3 - Aspecto visual da membrana posicionada da forma ideal sob a área a ser reparada.

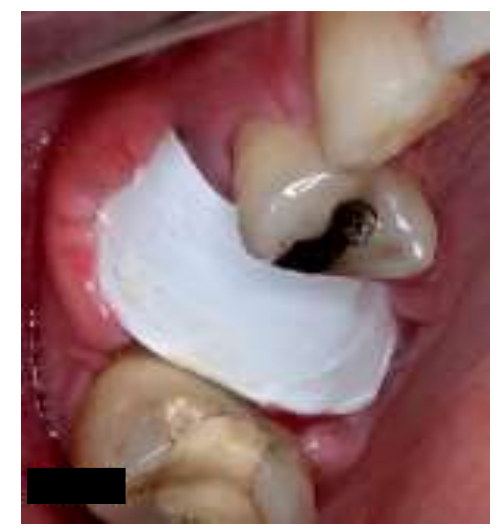

Fonte: Petrilli et al. (2018).

$4^{\circ}$ Passo: Realizar a sutura dos retalhos, preferencialmente a barreira deverá ficar exposta ao meio bucal, o que permitirá a regeneração dos tecidos moles (Figura 4). A sutura dos retalhos deverá ser feita sem tensionar o tecido, formando uma rede sobre a barreira, apenas para impedir seu deslocamento do sítio a ser regenerado.

Figura 4 - Membrana no local do defeito ósseo após sutura.

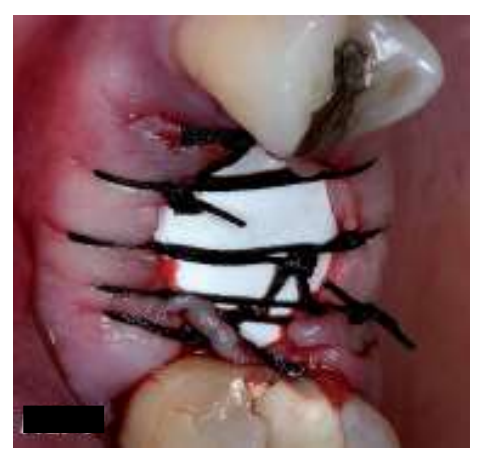

Fonte: Petrilli et al. (2018).

$5^{\circ}$ Passo: Remoção da membrana após no mínimo sete dias (Figura 5). Imediatamente após a remoção das suturas, a remoção da barreira deve ser feita delicadamente no sentido vertical, através de uma de suas bordas com pinça estéril e descartá-la conforme legislação vigente. Após a remoção da barreira, deve observar-se o tecido de granulação. Se o mesmo não for encontrado, a quantidade do coágulo sob a barreira foi insuficiente e aconselha-se a curetagem, de forma delicada, da área do defeito e a repetição do procedimento sob anestesia local com a utilização de uma nova membrana Bone Heal®. Caso a técnica de aplicação e proservação sejam realizadas corretamente, dentro de dois meses já é possível verificar, radiograficamente, progressão no processo de reparação óssea (Figura 6). 
Figura 5 - Aspecto visual do coágulo após 10 dias de pós-operatório.

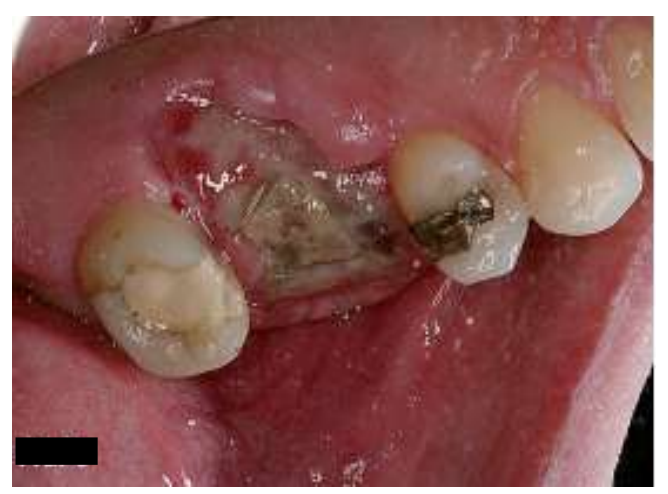

Fonte: Petrilli et al. (2018).

Figura 6 - Foto da panorâmica após 60 dias de pós.

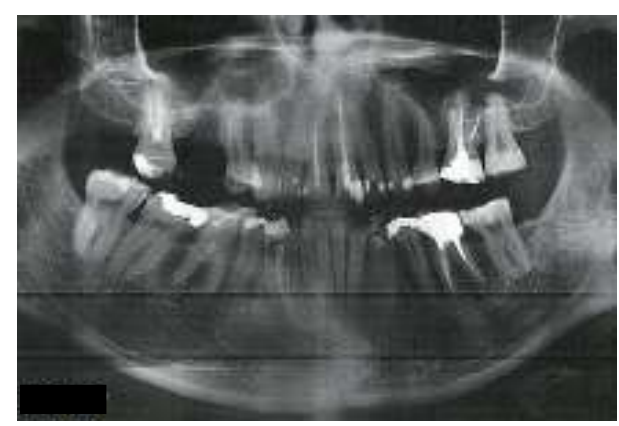

Fonte: Petrilli et al. (2018).

Alguns cuidados devem ser tomados:

A membrana deve ser utilizada somente em um único paciente;

Não utilizar as sobras dos recortes;

Após recorte, se a mesma não for utilizada imediatamente, deverá ser mantida submersa em soro fisiológico estéril;

Assim que removida da embalagem, deverá ser utilizada em até quatro horas;

Após 24 horas do término da cirurgia, orientar o paciente a realizar dois bochechos, de forma delicada, com gluconato de clorexidina à $0,12 \%$ com duração de 30 s cada, de oito em oito horas até a remoção da membrana.

\section{Conclusão}

Concluímos que a utilização da membrana Bone Heal® auxilia na manutenção do coágulo sanguíneo no alvéolo e com isso permite que o processo de regeneração óssea ocorra de maneira dinâmica e sem interferências, diminuindo riscos de perda óssea acentuada pós exodontia. Todavia, muitos estudos e relatos ainda devem ser realizados para assegurarem ainda mais a eficácia da membrana e sua propagação entre os profissionais da Odontologia.

\section{Referências}

Anjos, L. M. dos., Rocha, A. O., Lima, T. O., Santos, R. M. A., Rocha, M. N. O., Meneses, N. S. J., Oliveira, M. A., \& et al., (2021). Enxertos ósseos em odontologia - uma revisão integrativa da literatura. Research, Society and Development, 10(12), e522101220954. https://doi.org/10.33448/rsd-v10i12.20954

Bone Heal (2021). Boneheal. https://boneheal.com.br/boneheal.php. 
Carvalho, P., Perri, de S., Ponzoni, D., Bassi, A. P. F. \& Carvalho, M. C. A. (2004). Manutenção de volume do processo alveolar após exodontia com raspa de osso cortical autógeno. Implant News, 1(1):53-8.

Carvalho, M. A. (2012). Regeneração óssea guiada após exodontia utilizando membranas de polipropileno - Bone Heal. Monografia apresentada a FAPES. 39f. Especialização em Implantodontia. São Paulo.

Castro-Silva, I. I., Araújo, L. K., Souza, F. F. P., Ponte, J. S., Sousa, E. M., Jiménez, H. G. Q, Ferreira, F. V. \& et al., (2021). Pesquisa odontológica brasileira em regeneração óssea guiada: um estudo bibliométrico de quatro décadas. Research, Society and Development, $10(2)$, e25510212504. http://dx.doi.org/10.33448/rsd-v10i2.12504

Correia, H. R. D. C. (2016). Prevenção da Reabsorção óssea Alveolar Pós-Extração Dentária. Dissertação (Mestrado em Medicina Dentária) - Universidade Fernando Pessoa Faculdade de Ciências da Saúde Porto.

Costa, J. B. Z., Silva, F., Dultra, C. A. Souza L. F. \& Santos, M. C. N. E. (2016). O uso de membranas biológicas para regeneração óssea guiada em implantodontia: Uma revisão de literatura. Rev. Bahiana de Odontologia.

Del Rio Rocha, D. G., Romero, A. B. \& Díaz, A. C. (2020). Alveolar biomodification as an indispensable procedure before guided bone regeneration. Revista Cubana de Estomatología, Ciudade de La Habana, 57 (3), e2083.

Elgali, I., Omar, O., Dahlin, C. \& Thomsen, P. (2017). Guided bone regeneration: materials and biological mechanisms revisited. Eur J Oral Sci, 125(5):315337.

Fernandes, D. S. C, Klein, G. V., Lippert, A. O. Medeiros, N. G. \& Oliveira, R. P. (2010). Motivo do atendimento odontológico na primeira infância. Stomatos [online], 16(30), 04-10. http://revodonto.bvsalud.org/scielo.php?script=sci_arttext\&pid=S1519-44422010000100002.

Gusmão, C. V. B. \& Belangero, W. D (2009). Como a célula óssea reconhece o estímulo mecânico? Artigo de Atualização. Revista Brasileira de Ortopedia. 44(4). 2009. https://www.scielo.br/j/rbort/a/8D45D6sCCKtcj596q5MmJKR/?lang=pt.

Henn, J. D. (2010). Bioquímica do tecido animal. Seminário apresentado (Pós-Graduação em Ciências Veterinárias) - Universidade Federal do Rio Grande do Sul.

Judas, F. (2012). Estrutura e dinâmica do tecido ósseo. Texto de apoio para os alunos do Mestrado Integrado em Medicina Disciplina de Ortopedia. Coimbra: Clínica Universitária de Ortopedia.

Lacerda, E. J. R., Lacerda, H. M. \& Salomão, M. (2012). Invaginação de tecido conjuntivo após levantamento de seio maxilar, uso de biomateriais e implante tardio: resolução cirúrgica de um caso clínico. Implant News. 9(6): 843-50.

Lam, R. V. (1960). Contour changes of the alveolar processes following extractions. The Journal of Prosthetic Dentistry, 10(1), 25-32.

Lindhe, J., Lang, N. \& Tarring, T. (2010) Tratado de Periodontia Clínica e Implantodontia Oral. Rio de Janeiro: Editora Guanabara Koogan S.A.

Liu, J. \& Kerns, D. G. (2014). Mechanisms of guided bone regeneration: a review. Open Dent J., 16;8:56-65.

Martinez, E. C. (2013). Regeneração óssea guiada após exodontia e o uso de barreira de polipropileno - BONE HEAL®. Trabalho de Conclusão de Curso (Graduação em Odontologia) - Universidade Nove de Julho.

Marzola, C. (2008). Fundamentos de Cirurgia Buco Maxilo Facial. Ed. Gráfica Big Forms, 6 vs.

NesI H., Oliveira, M. T. \& Molina, G. O. (2013). Avaliação do uso de membranas na infiltração de tecido conjuntivo em alvéolos de dentes recém-extraídos. Rev. Bras. Odontol. 70(2), 136-41.

Ortega, M. J., Pérez, P. T., Mareque, B. S., Hernandez, A. F., Ferrés, P. E. (2012). Immediate implants following tooth extraction. A systematic review. Med Oral Patol Oral Cir Bucal, 1;17(2):e251-61.

Pereira, A. S., Shitsuka, D. M., Parreira, F. J. \& Shitsuka, R. (2018). Metodologia da pesquisa científica.

Petrilli, G., Petrilli, L. R. F. Salomão, M. \& Siqueira, J. T. T. (2018). Regeneração Óssea guiada com barreira de Polipropileno e instalação de Implante Flap Less. Revista Catarinense de Odontologia. 18(18).

Pilger, A. D., Schneider, L. E., Silva, G. M., Schneider, K. C. \& Smidt, R. (2020). Membranas e barreiras para regeneração óssea guiada. Revista de Ciências Médicas e Biológicas, 19(3), 441-448.

Salomão, M. (2010). Bone Heal®: Barreira Regenerativa. Abbott: A promise for life.

Salomão, M. \& Siqueira, J. T. T. (2009). Uso de barreira de polipropileno pós exodontia. Relato de três casos clínicos. Rev. Brás. Implant.

Salomão, M. \& Siqueira, J. T. T. (2010). Recuperação do rebordo alveolar através de barreira exposta ao meio bucal. Novo paradigma? Revista Catarinense de Implantodontia. 10 anos. $\mathrm{n}^{\circ} 12$.

Salomão, M. \& Siqueira, J. T. T. (2010). Regeneração óssea guiada através de barreira exposta ao meio bucal após exodontias. Relato de caso. Rev. Brás. Implant.

Salomão, M. \& Siqueira, J. T. T. (2010). Uso de barreira exposta ao meio bucal para regeneração óssea guiada após a exodontia. Rev. Assoc. Paul. Cir. Dent., 64(3):184-8. 
Salomão, M., Siqueira J. T. T. \& Alvarez F. K. (2010). Regeneração óssea guiada em defeitos extensos pós exodontias utilizando membrana exposta ao meio bucal. Revista ImplantNews, 7(6):753-9.

Salomão, M., Siqueira, J. T. T. \& Junior C. L. (2010). Mudança de paradigma na Regeneração Óssea Guiada. Essencial em revista -Ano 8 , n 38 - APCD Jardim Paulista.

Santos, E. R. S, Silva, F. R., Cordeiro, J. J. N. C. \& Silva, L. C. (2019). Perda dentária e qualidade de vida: revisão de literatura. Trabalho de Conclusão de Curso (Graduação em Odontologia) - Centro Universitário de Anápolis Unievangélica. Anápolis - GO.

Santos, G. C. (2014). Eficiência da clorexidina como agente de controle bacteriano nas barreiras de polipropileno (Bone Heal®). Trabalho de Conclusão de Curso (Especialização em Implantodontia) - Faculdade Meridional. Chapecó - SC.

Santos, J. U. (2012). Atuais paradigmas na preservação alveolar pós exodontia previamente à instalação de implantes: uma revisão de literatura. Trabalho de Conclusão de Curso (Especialização em Implantodontia). Curso de Odontologia da Escola Baiana de Medicina e Saúde Pública. Salvador - BA.

Schropp, L., Wenzel, A., Kostopoulos, L. \& Karring, T. (2003). Bone healing and soft tissue contour changes following single-tooth extraction: A clinical and radiographic 12-month prospective study. Int. J. Periodontics Restor. Dent., 23:313-323

Soares, R. D., Salomão, M. \& Siqueira, J. T. T. (2019). Instalação de implante imediato em septo inter-radicular associada à regeneração óssea guiada com barreira de polipropileno. Relato de caso clínico. Rev. Catarinense de Implantodontia. 68-70.

Todescan, F. F., Bechelli, A. \& Romanelli, H. (2005). Implantodontia Contemporânea: Cirurgia e Prótese. Editora Artes Médicas Ltda.

Tumenas, I, Pascotto, R., Saade, L. J. \& Bassani, M. (2014). Odontologia Minimamente Invasiva. Rev Assoc Paul Cir Dent., 68(4):283-95.

Vargas, J. (2016). Membranas de uso en regeneración ósea guiada. Odontología Vital. San Pedro, Lourdes de Montes de Oca, $24,35-42$.

Zeppini, L. A. S. (2014). Barreira de polipropileno - Uma nova abordagem para regeneração óssea guiada (ROG). Rev. Odontologia (ATO). 14(5), 301/30. 